H. CAO, Y, KUANG, X, SHI, K, L. WONG, B, B. TAN, J. M. C. KWAN, X, LIU, J. WU* (NATIONAL UNIVERSITY OF SINGAPORE, REPUBLIC OF SINGAPORE, AND NATIONAL UNIVERSITY OF SINGAPORE (SUZHOU) RESEARCH INSTITUTE, SUZHOU, P. R. OF CHINA) Photoinduced Site-Selective Alkenylation of Alkanes and Aldehydes with Aryl Alkenes Nat. Commun. 2020, 11, DOI: 10.1038/s41467-020-15878-6z.

\section{Dual-Catalyst Photoinduced Alkenylation of Alkanes and Aldehydes via C-H Activation}

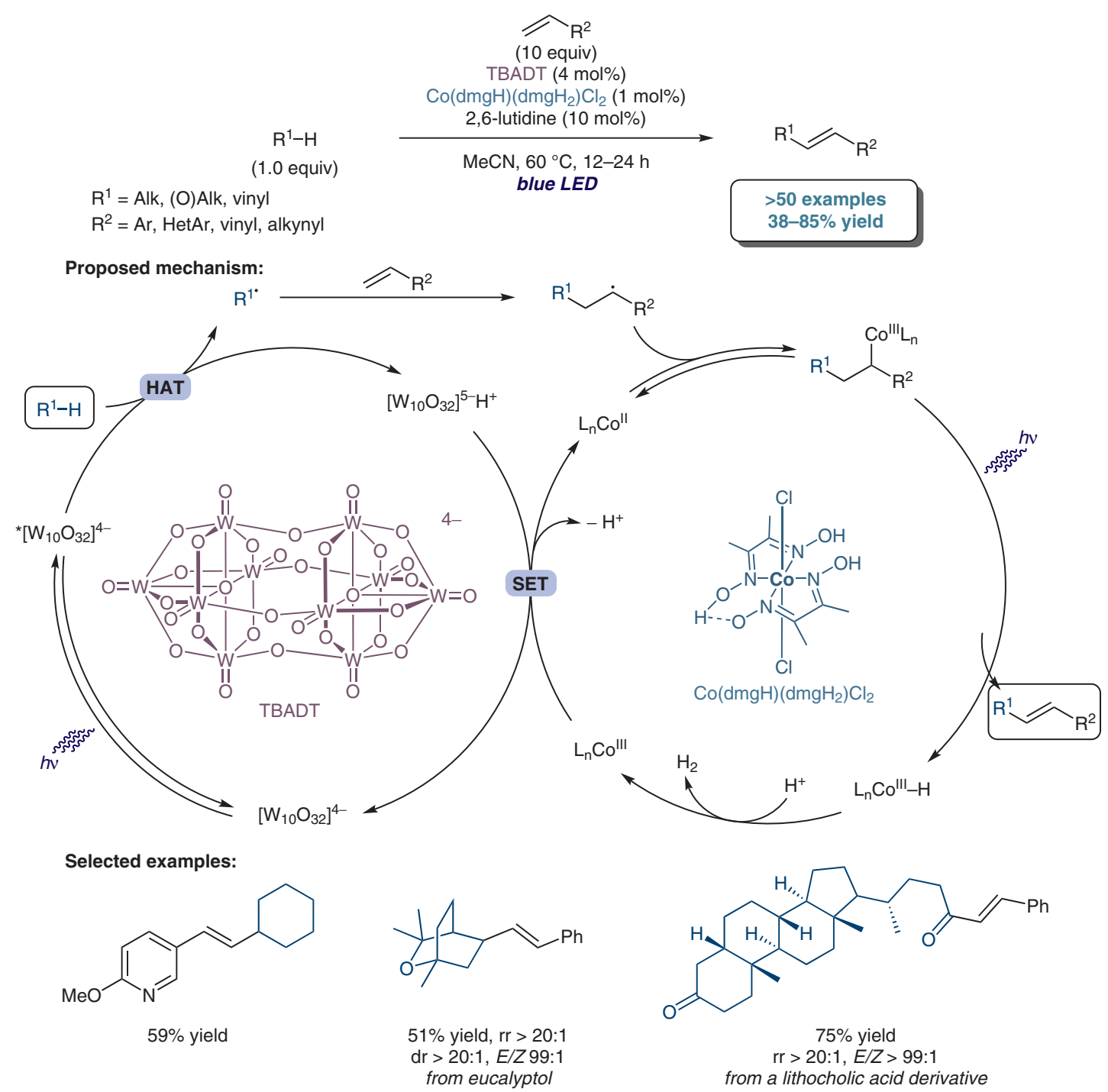

\section{Category}

Metals in Synthesis

\section{Key words}

photoredox

alkenylation

$\mathrm{C}-\mathrm{H}$ activation
Significance: The authors report a site-selective photoinduced alkenylation of various alkanes and aldehydes with aryl and heteroaryl alkenes. This dehydrogenative reaction utilizes two photoactive catalysts (tetra-n-butylammonium decatungstate (TBADT) as HAT agent and $\left.\mathrm{Co}(\mathrm{dmgH})\left(\mathrm{dmgH}_{2}\right) \mathrm{Cl}_{2}\right)$, which eliminates the need for an external oxidant.
Comment: This mild alkenylation was used for the late-stage functionalization of diverse complex molecules, while still ensuring a high level of siteselectivity for the sterically most accessible and most electron-rich $\mathrm{C}-\mathrm{H}$ bond. Wu and co-workers propose a mechanism that involves cooperation of the tungstate and the cobalt catalysts. 